\title{
Conducting Block Copolymer Binders for Carbon-Free Hybrid Vanadium Pentoxide Cathodes with Enhanced Performance
}

\author{
Hyosung An, ${ }^{\dagger}$ Xiaoyi Li, ${ }^{\ddagger}$ Cody Chalker,${ }^{\circledR}$ Maria Stracke,${ }^{\dagger}$ Rafael Verduzco, ${ }^{* *_{\perp}}$ and Jodie L. \\ Lutkenhaus ${ }^{*}{ }_{\|}$ \\ ${ }^{\dagger}$ Artie McFerrin Department of Chemical Engineering, Texas A\&M University, College Station, \\ Texas 77843, United States *E-mail: jodie.lutkenhaus@tamu.edu \\ ${ }^{\ddagger}$ Department of Chemical and Biomolecular Engineering, Rice University, Houston, Texas 77005, \\ United States *E-mail: rafaelv@rice.edu \\ ${ }^{\S}$ Department of Chemistry, Texas A\&M University, College Station, Texas 77843, USA. \\ ${ }^{\lrcorner}$Department of Materials Science and NanoEngineering, Rice University, Houston, Texas 77005, \\ United States \\ "Department of Materials Science and Engineering, Texas A\&M University, College Station, Texas \\ 77843, United States
}

Figure S1. XPS spectra of (a) as-prepared $\mathrm{V}_{2} \mathrm{O}_{5}$ xerogel and (b) O 1s and V 2p core peaks. (c) XRD patterns of asprepared $\mathrm{V}_{2} \mathrm{O}_{5}$ xerogel.

Figure S2. (a) Preparation of water dispersible P3HT. (b) DLS of $0.05 \mathrm{mg} / \mathrm{ml}$ of dispersed P3HT shows that the average diameter is $151 \mathrm{~nm}$. (c) A SEM image of P3HT dispersion particles.....

Figure S3. (a) Cyclic voltammetry and (b) discharge capacity and coulombic efficiency of a pure P3HT- $b$-PEO.. S-3

Figure S4. FT-IR spectra of as-prepared $\mathrm{V}_{2} \mathrm{O}_{5}, \mathrm{PEO} / \mathrm{V}_{2} \mathrm{O}_{5}, \mathrm{P} 3 \mathrm{HT} / \mathrm{V}_{2} \mathrm{O}_{5}, \mathrm{PEO}+\mathrm{P} 3 \mathrm{HT} / \mathrm{V}_{2} \mathrm{O}_{5}, \mathrm{P} 3 \mathrm{HT}-b-\mathrm{PEO} / \mathrm{V}_{2} \mathrm{O}_{5}(\mathrm{P} 5$,

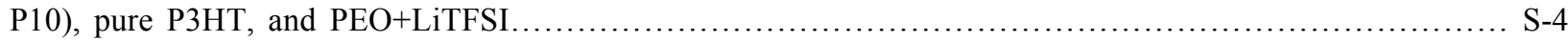

Table S1. Characteristic absorption bands and assignment of FT-IR spectra of PEO homopolymer with LiTFSI and

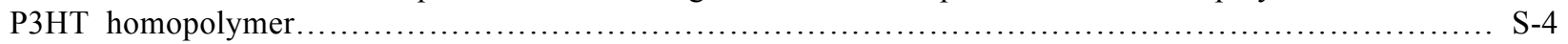

Figure S5. Cyclic voltammograms of $\mathrm{V}_{2} \mathrm{O}_{5}, \mathrm{P} 5$, and $\mathrm{P} 10$ before and after cycling at various scan rates.......... S-5

Figure S6. Plots of $v^{0.5}$ vs. $i(V) / v^{0.5}$ for determining $a_{1}$ and $a_{2}$ at given potentials........................... S-5

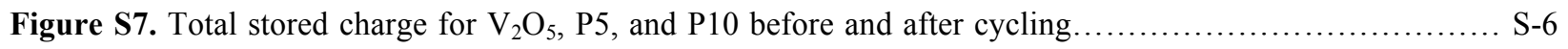

Figure S8. Plots of $\log v$ vs. $\log i(V)$ for determining $a$ and $b$ of $\log i(V)=b \log v+\log a$ at given potentials... S-6

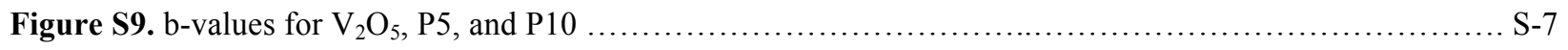

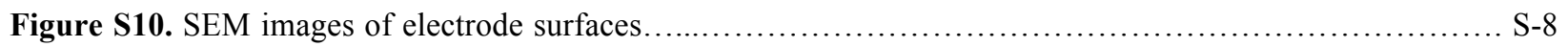

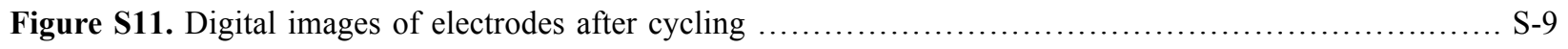

Figure S12. XPS data of the V 2p peak for various electrodes........................................... S-10

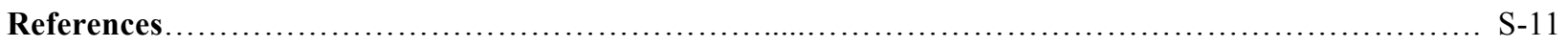


(a)

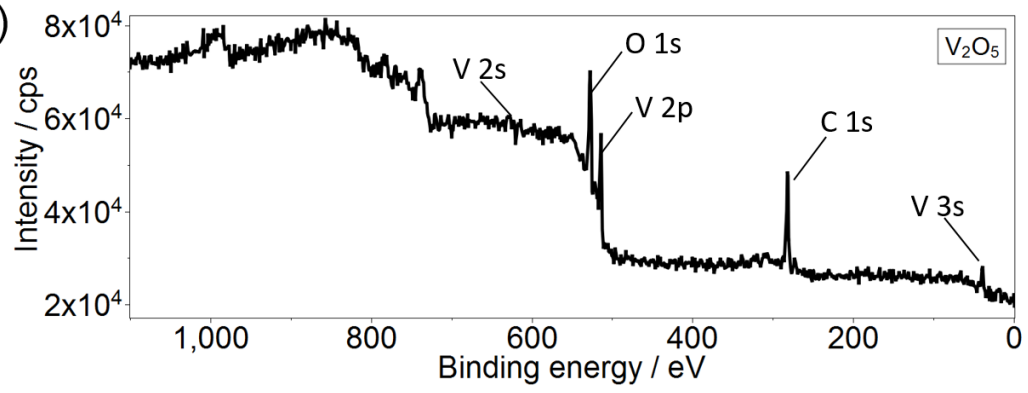

(b)

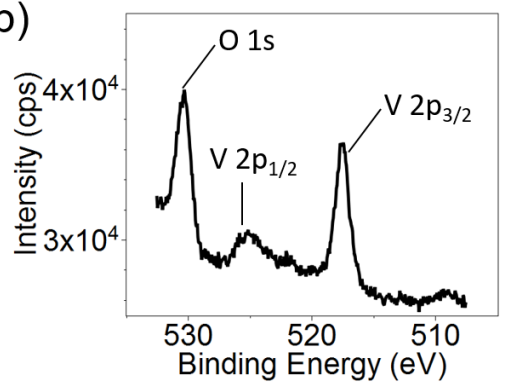

(c)

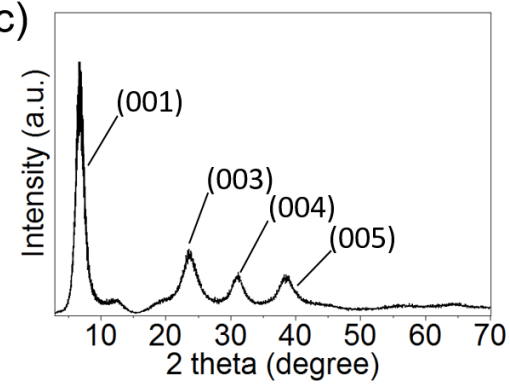

Figure S1. XPS spectra of (a) as-prepared $\mathrm{V}_{2} \mathrm{O}_{5}$ xerogel and (b) $\mathrm{O} 1 \mathrm{~s}$ and $\mathrm{V} 2 \mathrm{p}$ core peaks. (c) XRD patterns of asprepared $\mathrm{V}_{2} \mathrm{O}_{5}$ xerogel.

We characterized the as-prepared $\mathrm{V}_{2} \mathrm{O}_{5}$ xerogel using X-ray photoelectron spectroscopy (XPS) and X-ray diffraction (XRD). XPS spectra of as-prepared $\mathrm{V}_{2} \mathrm{O}_{5}$ xerogel (Figure $\mathrm{S} 1 \mathrm{a}$ and $\mathrm{S} 1 \mathrm{~b}$ ) shows peaks attributed to the core levels of $\mathrm{V} 2 \mathrm{p}, \mathrm{V} 2 \mathrm{~s}, \mathrm{~V} 3 \mathrm{~s}, \mathrm{O} 1 \mathrm{~s}$, and $\mathrm{C} 1 \mathrm{~s}$. The binding energy of $\mathrm{V} 2 \mathrm{p} 3 / 2$ is $516.9 \mathrm{eV}$ corresponding to the $\mathrm{V}^{5+}$ valance state. ${ }^{1}$ The XRD shows clearly a hydrated layered structure with (001) reflection peaks for $\mathrm{V}_{2} \mathrm{O}_{5}$ synthesized by $\mathrm{H}_{2} \mathrm{O}_{2}$ method, Figure S1c. The major peak is located at $6.88^{\circ}$ and the d-spacing is calculated to be about $12.8 \AA$. This XRD plot is consistent with JCPDS No. 40-1296 hydrated layer-structured $\mathrm{V}_{2} \mathrm{O}_{5}$. These XPS and XRD data of $\mathrm{V}_{2} \mathrm{O}_{5}$ xerogel are in good agreement with the reported studies. ${ }^{1-4}$ 
(a)

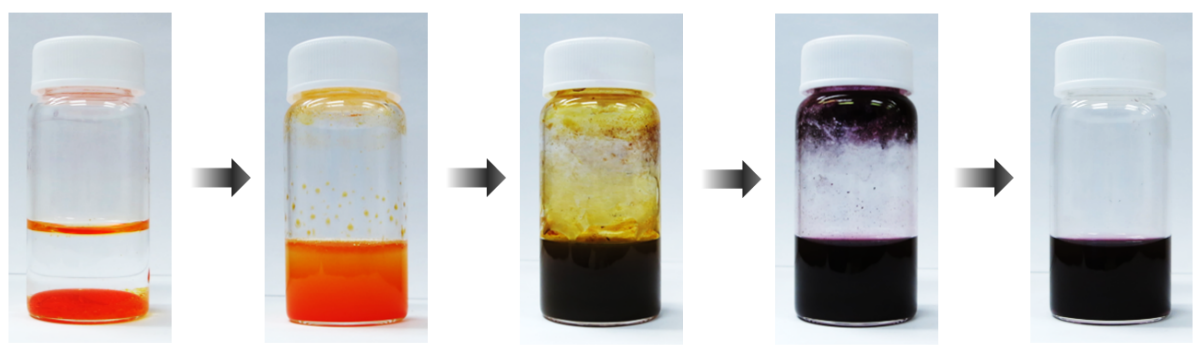

(b)

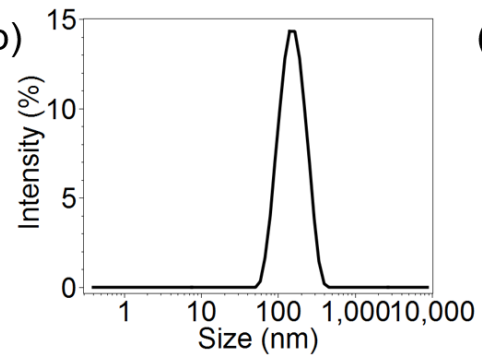

(c)

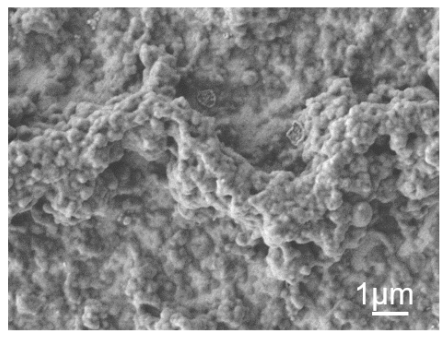

Figure S2 (a) Preparation of water-dispersible P3HT. (b) Dynamic light scattering (DLS) of $0.05 \mathrm{mg} / \mathrm{ml}$ of dispersed P3HT shows that the average diameter is $151 \mathrm{~nm}$. (c) SEM image of P3HT drop-cast from dispersion.

The $1 \mathrm{ml} \mathrm{P} 3 \mathrm{HT}$ solution in chloroform $(1 \mathrm{mg} / \mathrm{ml})$ with $6 \mathrm{ml}$ Milli-Q water was sonicated at room temperature with the lid open in order to evaporate the chloroform. At the beginning of sonication, the chloroform layer (orange layer seen in Figure S2a) and the water layer were partially mixed. As the chloroform evaporated, the solution changed from a bright orange color to a purple color. In order to remove the residual chloroform, the solution was sonicated for another 10 minutes after the color change. After sonication, the P3HT dispersion was transferred to new vial (last digital images of Figure S2a). The solution was stable for 2 days.

(a)

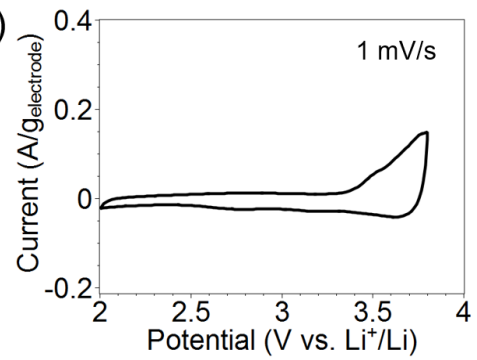

(b)

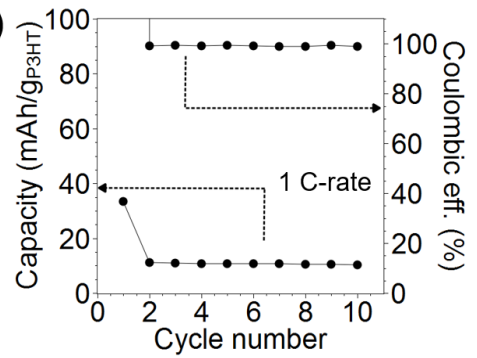

Figure S3. (a) Cyclic voltammetry and (b) discharge capacity and coulombic efficiency of pure P3HT-b-PEO. 


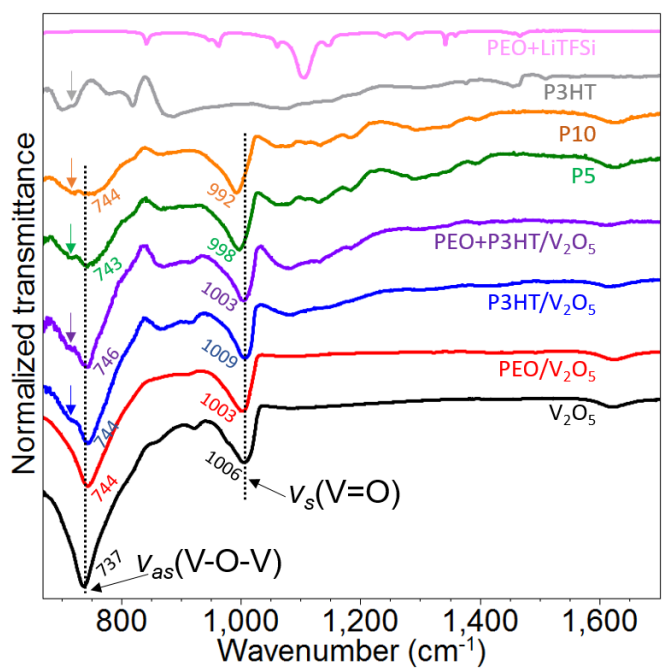

Figure S4. FT-IR spectra of as-prepared $\mathrm{V}_{2} \mathrm{O}_{5}, \mathrm{PEO} / \mathrm{V}_{2} \mathrm{O}_{5}, \mathrm{P} 3 \mathrm{HT} / \mathrm{V}_{2} \mathrm{O}_{5}, \mathrm{PEO}+\mathrm{P} 3 \mathrm{HT} / \mathrm{V}_{2} \mathrm{O}_{5}, \mathrm{P} 3 \mathrm{HT}-b-\mathrm{PEO} / \mathrm{V}_{2} \mathrm{O}_{5}(\mathrm{P} 5$, P10), pure P3HT, and PEO+LiTFSI.

Table S1. Characteristic absorption bands and assignment of FT-IR spectra of PEO homopolymer with LiTFSI and P3HT homopolymer. ${ }^{5-7}$

\begin{tabular}{|c|c|c|c|c|c|}
\hline Material & $\begin{array}{l}\text { Wavenum } \\
\text { ber }\left(\mathrm{cm}^{-1}\right)\end{array}$ & Functional group & Material & $\begin{array}{l}\text { Wavenumb } \\
\text { er }\left(\mathrm{cm}^{-1}\right)\end{array}$ & Functional group \\
\hline \multirow{5}{*}{$\begin{array}{l}\text { PEO+ } \\
\text { LiTFSI }\end{array}$} & \multirow{2}{*}{$\begin{array}{l}1467 \\
1360,1342 \\
1280,1242\end{array}$} & \multirow{2}{*}{$\begin{array}{l}\text {-CH2- bending (scissoring) } \\
\text { - } \mathrm{CH} 2 \text { - bending (wagging) } \\
\text { - } \mathrm{CH} 2 \text { - bending (twisting) }\end{array}$} & \multirow{5}{*}{ P3HT } & 1510 & $\begin{array}{l}\mathrm{C}=\mathrm{C} \text { thiophene ring } \\
\text { asymmetric stretching }\end{array}$ \\
\hline & & & & 1455 & $\begin{array}{l}\mathrm{C}=\mathrm{C} \text { thiophene ring } \\
\text { symmetric stretching }\end{array}$ \\
\hline & $\begin{array}{l}1148, \\
1107,1061\end{array}$ & C-O-C asymmetric stretching & & 1377 & Aliphatic $-\mathrm{CH}_{3}$ bending \\
\hline & 963 & $\begin{array}{l}\text {-CH2- asymmetric stretching } \\
\text { and -CH2- bending (rocking) }\end{array}$ & & 820 & $\begin{array}{l}\text { Aromatic C-H bending } \\
\text { out of plain }\end{array}$ \\
\hline & 842 & $\mathrm{C}-\mathrm{O}-\mathrm{C}$ symmetric stretching & & 716 & $\begin{array}{l}\text { Aliphatic-CH2- bending } \\
\text { (rocking) }\end{array}$ \\
\hline
\end{tabular}



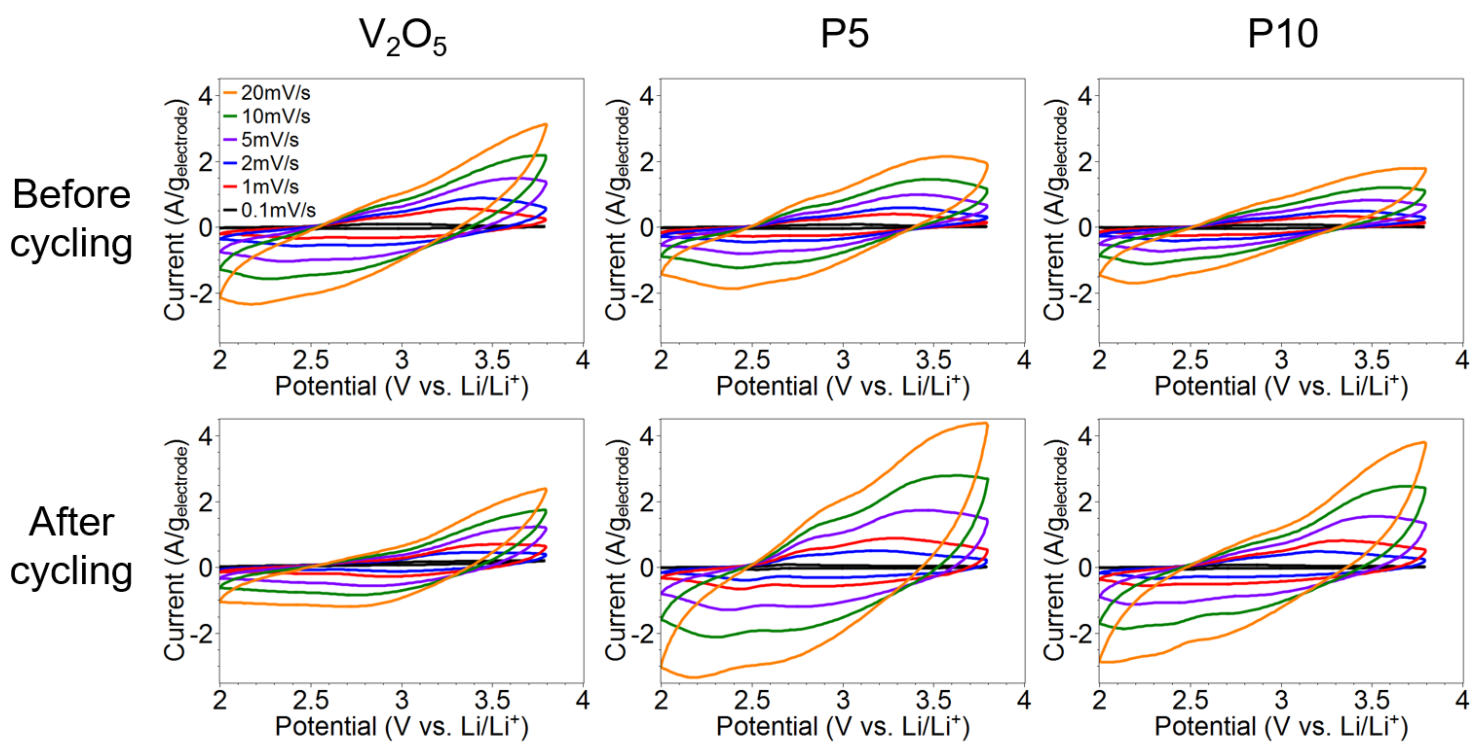

Figure S5. Cyclic voltammograms of $\mathrm{V}_{2} \mathrm{O}_{5}, \mathrm{P} 5$, and $\mathrm{P} 10$ before and after cycling at various scan rates.

We investigated the charge storage contribution attributed to intercalation and capacitive behaviors. In cyclic voltammetry, the current response $i(V)$ as a function of given potential $V$ at different scan rates can be expressed as the sum of both intercalation $\left(a_{1} v^{0.5}\right)$ and capacitive contributions $\left(a_{2} v\right)$ as shown below:

$$
i(V)=a_{1} v^{0.5}+a_{2} v
$$

where $i(V)$ is the current response at a given potential in the CV curve, $v$ is the scan rate, and $a_{1}$ and $a_{2}$ are adjustable constants. $i(V)=a_{1} v^{0.5}+a_{2} v$ was rearranged into $i(V) / v^{0.5}=a_{1}+a_{2} v^{0.5}$, and then plots of $i(V) / v^{0.5}$ vs. $v^{0.5}$ were drawn at various potentials and scan rates using CV data (Figure S5), yielding Figure S6. $a_{l}$ (y-axis intercept) and $a_{2}$ (slope) were determined by linear fitting. Based on the calculated $a_{1}$ and $a_{2}$ values, intercalation $\left(a_{l} v^{0.5}\right)$ and capacitive contributions $\left(a_{2} v\right)$ can be calculated at a given scan rate and a given potential, Figure S5. Figure S7 shows the total charge stored and both capacitive and intercalation contributions calculated by integrating CV curves from Figure S5.
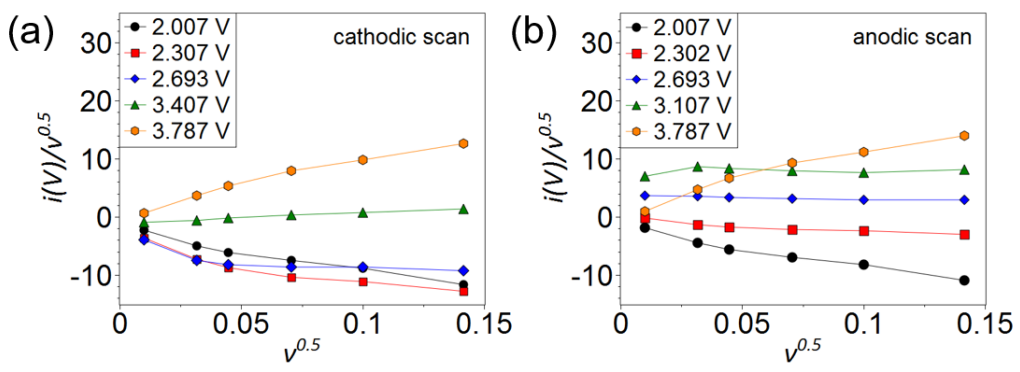

Figure S6. Plots of $v^{0.5}$ vs. $i(V) / v^{0.5}$ from (a) cathodic and (b) anodic scans in cyclic voltammetry, which were used for determining $a_{1}$ and $a_{2}$ from $i(V) / v^{0.5}=a_{1}+a_{2} v^{0.5}$ at given potentials. The current responses were obtained from cyclic voltammetry at various scan rates of 0.1 to $20 \mathrm{mV} / \mathrm{s}$. 

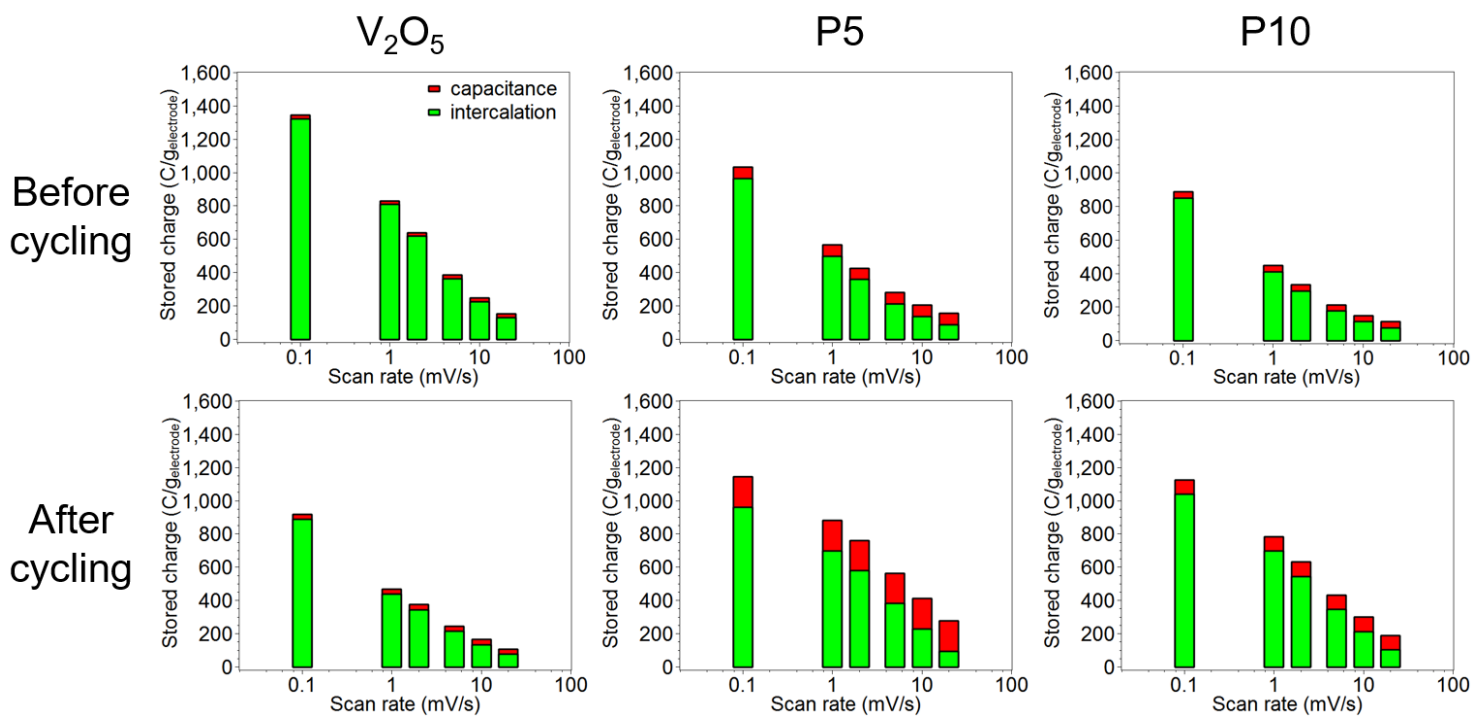

Figure S7. Total stored charge for $\mathrm{V}_{2} \mathrm{O}_{5}, \mathrm{P} 5$, and $\mathrm{P} 10$ before and after cycling as a function of scan rate.

The b-value calculation provides information on whether the current response $i(V)$ from cyclic voltammetry is controlled by faradaic (intercalation) and/or non-faradaic processes (capacitive) processes. ${ }^{8-10}$ The current response $i(V)$ can be expressed using the power law as shown below:

$$
i(V)=a v^{b}
$$

where $i(V)$ is the current response at a given potential in the cyclic voltammogram, $v$ is the scan rate, and $a$ and $b$ are adjustable constants. $i(V)=a v^{b}$ was rearranged into $\log i(V)=b \log v+\log a$, and then plots of $\log v$ vs. $\log i(V)$ were drawn at various potentials and scan rates using CV data (Figure S5), Figure S8. $\log a$ (y-axis intercept) and $b$ (slope) were determined by linear fits. Figure S9 shows the determined b-values as a function of potential. In the case of $b=1$, the redox process is an ideal non-diffusion-limited process (such as pseudocapacitance). When $b=0.5$, $i(V)=a v^{0.5}$ satisfies the Cottrell equation. The redox process is an ideal diffusion-limited faradaic reaction (such as intercalation). For $\mathrm{V}_{2} \mathrm{O}_{5}$ in the anodic scan, the b-values of fresh electrodes were close to unity around $2 \mathrm{~V}$. The $\mathrm{b}$ value decreased to around 0.5 around $2.6 \mathrm{~V}$ and $3.2 \mathrm{~V}$, and then the b-value increased toward unity above $3.2 \mathrm{~V}$. This trends corresponds with the range of the $\mathrm{Li}^{+}$intercalation reaction for $\mathrm{V}_{2} \mathrm{O}_{5}$ xerogel electrode. ${ }^{11-13}$ Fresh $\mathrm{P} 5$ and $\mathrm{P} 10$ electrodes exhibit the same trend. After cycling, P5 and P10 electrodes had a higher b-value due to their faster response. This result corresponds to the results of charge storage contribution in Figure 5.
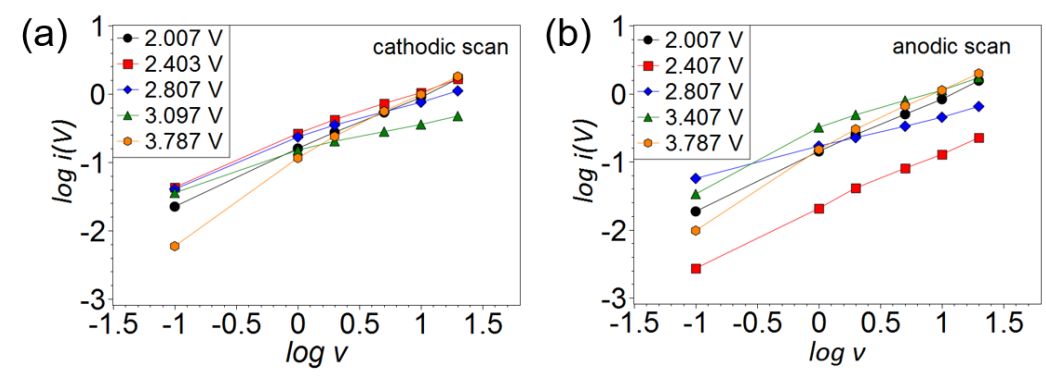

Figure S8. Plots of $\log v$ vs. $\log i(V)$ from (a) cathodic and (b) anodic scans in cyclic voltammetry, which were used for determining $a$ and $b$ of $\log i(V)=b \log v+\log a$ at given potentials. The current responses were obtained from cyclic voltammetry at various scan rates from 0.1 to $20 \mathrm{mV} / \mathrm{s}$. 
(a)

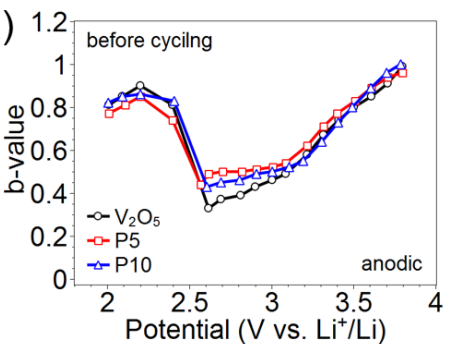

(c)

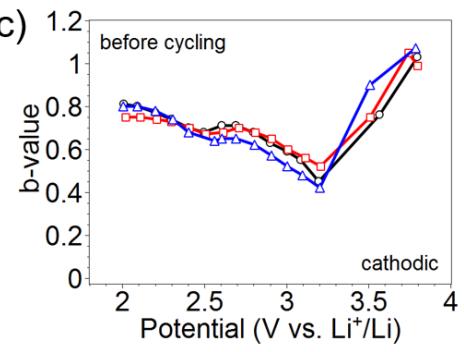

(b)

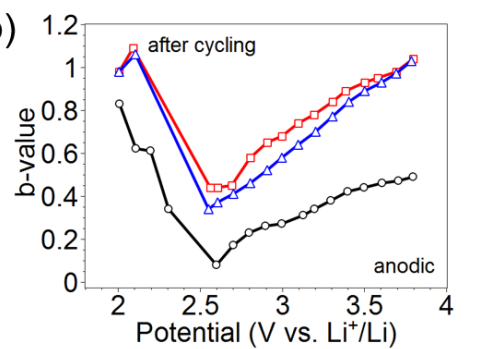

(d)

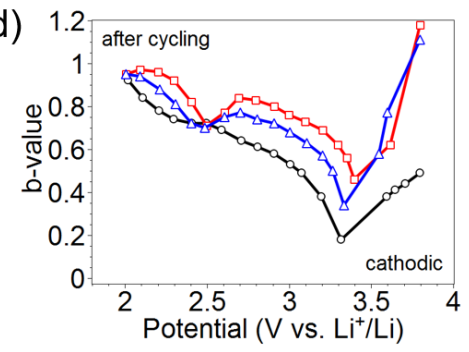

Figure S9. b-values for $\mathrm{V}_{2} \mathrm{O}_{5}, \mathrm{P} 5$, and P10 plotted as a function of voltage for anodic and cathodic sweeps before cycling and after cycling. 


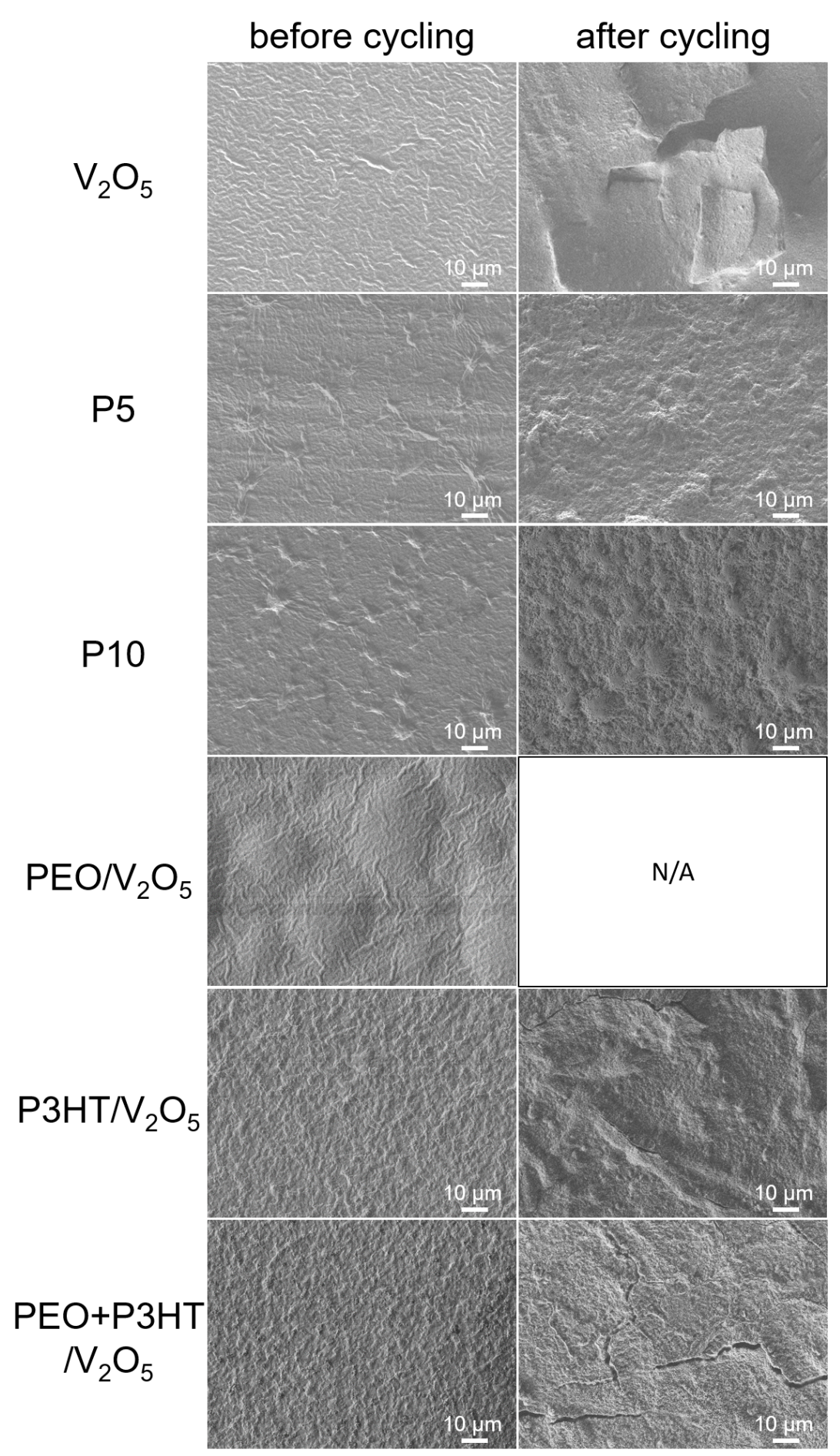

Figure S10. SEM images of $\mathrm{V}_{2} \mathrm{O}_{5}, \mathrm{P} 5, \mathrm{P} 10, \mathrm{PEO} / \mathrm{V}_{2} \mathrm{O}_{5}, \mathrm{P} 3 \mathrm{HT} / \mathrm{V}_{2} \mathrm{O}_{5}$, and $\mathrm{PEO}+\mathrm{P} 3 \mathrm{HT} / \mathrm{V}_{2} \mathrm{O}_{5}$ electrode surfaces before accelerated cycling (left) and after accelerated cycling (right). One set of accelerated cycling consists of 10 charge-discharge cycles at $1 \mathrm{C}$-rate and 1 charge-discharge cycle at $0.1 \mathrm{C}$-rate $(11$ total). 20 sets were performed (total 220 cycles). 


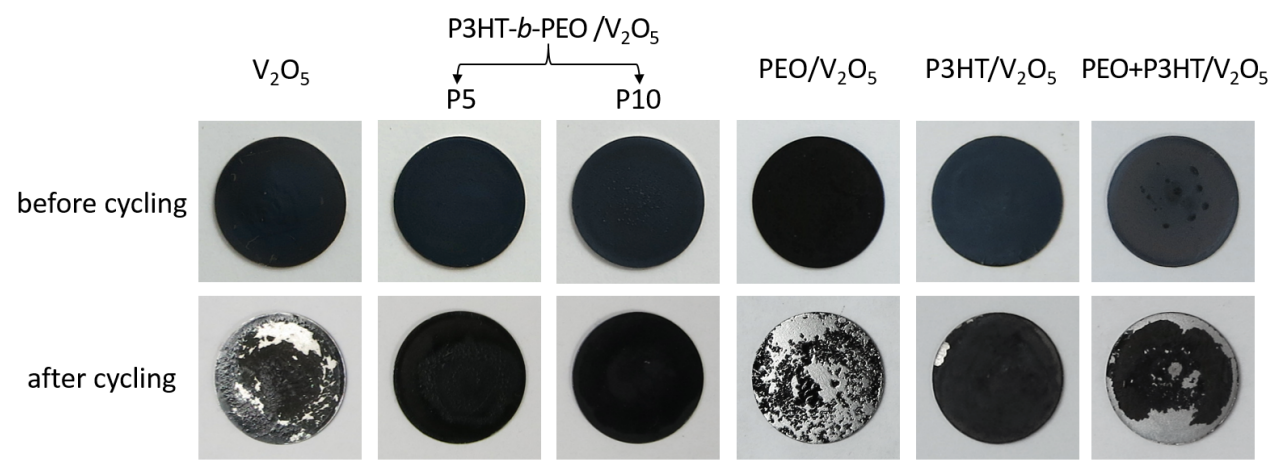

Figure S11. Digital images of $\mathrm{V}_{2} \mathrm{O}_{5}, \mathrm{P} 5, \mathrm{P} 10, \mathrm{PEO} / \mathrm{V}_{2} \mathrm{O}_{5}, \mathrm{P} 3 \mathrm{HT} / \mathrm{V}_{2} \mathrm{O}_{5}$, and $\mathrm{PEO}+\mathrm{P} 3 \mathrm{HT} / \mathrm{V}_{2} \mathrm{O}_{5}$ after cycling. 


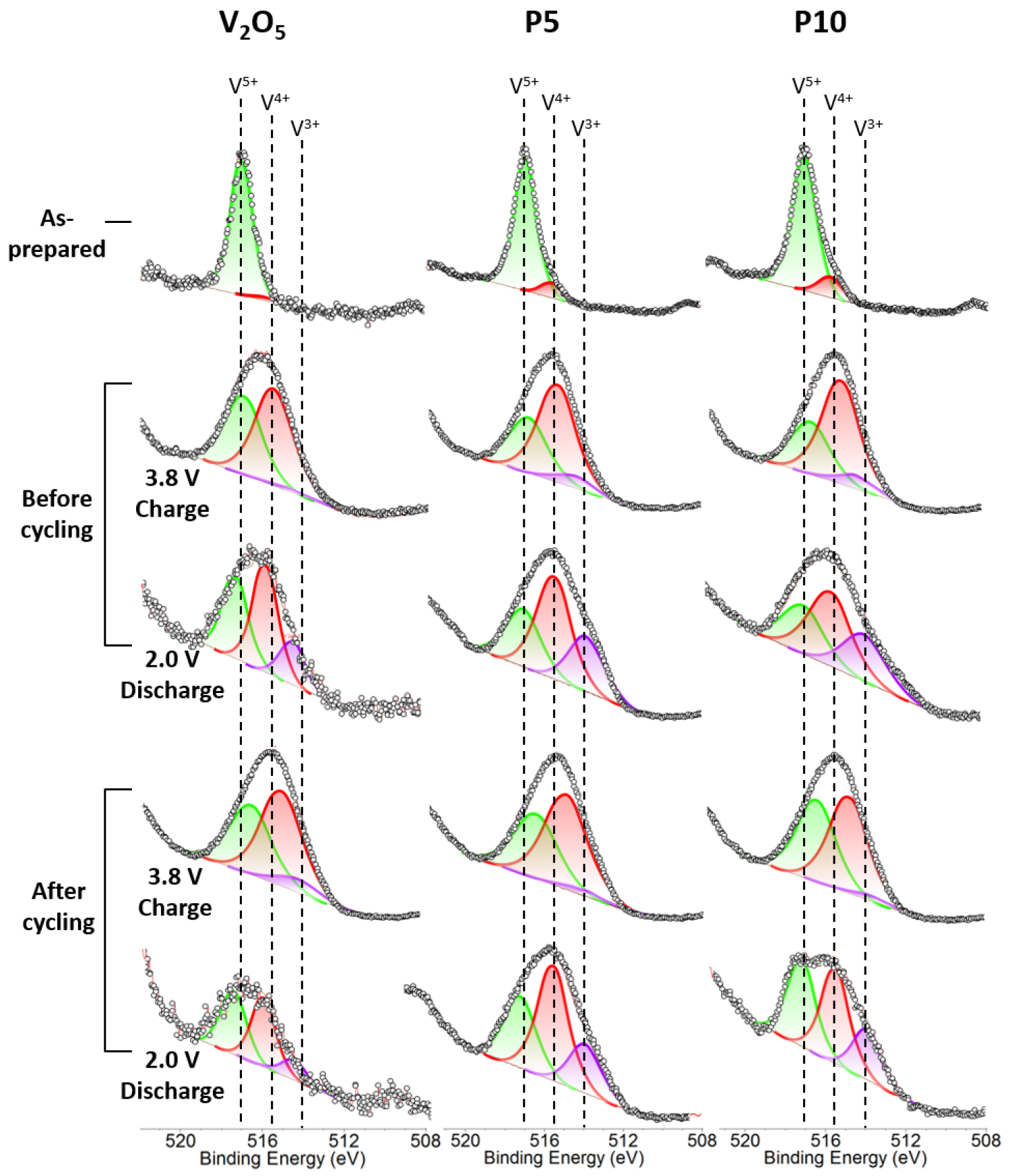

Figure S12. XPS of the V $2 p$ region if as-prepared electrodes before and after cycling at charged (3.8 V) and discharged $(2.0 \mathrm{~V})$ states. For curve fitting, a combined Gaussian-Lorentzian line shape (CasaXPS) and linear-type background were used with the same full-width-half-maximum (FWHM) for all components.

The average valence states of vanadium of the hybrid electrodes were calculated from the V $2 p$ spectra using the equation below:

$$
\mathrm{V}^{\mathrm{n}+}=\frac{5 \times \mathrm{V}^{5+}+4 \times \mathrm{V}^{4+}+3 \times \mathrm{V}^{3+}}{\mathrm{V}^{5+}+\mathrm{V}^{4+}+\mathrm{V}^{3+}}
$$

where $\mathrm{V}^{5+}, \mathrm{V}^{4+}$, and $\mathrm{V}^{3+}$ are the integrated peak areas for $\mathrm{V}^{5+}, \mathrm{V}^{4+}$, and $\mathrm{V}^{3+}$, respectively. 


\section{References}

(1) Lu, Y.-C.; Crumlin, E. J.; Veith, G. M.; Harding, J. R.; Mutoro, E.; Baggetto, L.; Dudney, N. J.; Liu, Z.; Shao-Horn, Y., In Situ Ambient Pressure X-Ray Photoelectron Spectroscopy Studies of Lithium-Oxygen Redox Reactions. Sci. Rep. 2012, 2, 715.

(2) Li, M.; Kong, F.; Wang, H.; Li, G., Synthesis ofVvanadium Pentoxide $\left(\mathrm{V}_{2} \mathrm{O}_{5}\right)$ Ultralong Nanobelts via an Oriented Attachment Growth Mechanism. CrystEngComm 2011, 13 (17), 5317-5320.

(3) Du, G.; Seng, K. H.; Guo, Z.; Liu, J.; Li, W.; Jia, D.; Cook, C.; Liu, Z.; Liu, H., Graphene-- ${ }_{2} \mathrm{O}_{5} \cdot \mathrm{nH}_{2} \mathrm{O}$ Xerogel Composite Cathodes for Lithium Ion Batteries. RSC Adv. 2011, 1 (4), 690-697.

(4) Oliveira, H.; Graeff, C.; Zanta, C.; Galina, A.; Gonçalves, P., Synthesis, Characterization and Properties of a Melanin-Like/Vanadium Pentoxide Hybrid Compound. J. Mater. Chem. 2000, 10 (2), $371-375$.

(5) Geng, Y.; Wang, G.; Cong, Y.; Bai, L.; Li, L.; Yang, C., Surface Adsorption-Induced Conformational Ordering and Crystallization of Polyethylene Oxide. J. Polym. Sci., Part B: Polym. Phys. 2010, 48 (2), 106112.

(6) Tamanai, A.; Beck, S.; Pucci, A., Mid-Infrared Characterization of Thiophene-Based Thin Polymer Films. Displays 2013, 34 (5), 399-405.

(7) Guo, Y.; Jin, Y.; Su, Z., Spectroscopic Study of Side-Chain Melting and Crystallization of Regioregular Poly (3-Dodecylthiophene). Polym. Chem. 2012, 3 (4), 861-864.

(8) Sathiya, M.; Prakash, A.; Ramesha, K.; Tarascon, J. M.; Shukla, A., $\mathrm{V}_{2} \mathrm{O}_{5}$-Anchored Carbon Nanotubes for Enhanced Electrochemical Energy Storage. J. Am. Chem. Soc. 2011, 133 (40), 16291-16299.

(9) Lindström, H.; Södergren, S.; Solbrand, A.; Rensmo, H.; Hjelm, J.; Hagfeldt, A.; Lindquist, S.-E., Li Ion Insertion in $\mathrm{TiO}_{2}$ (Anatase). 2. Voltammetry on Nanoporous Films. J. Phys. Chem. B 1997, 101 (39), 77177722 .

(10) Wang, J.; Polleux, J.; Lim, J.; Dunn, B., Pseudocapacitive Contributions to Electrochemical Energy Storage in $\mathrm{TiO}_{2}$ (Anatase) Nanoparticles. J. Phys. Chem. C 2007, 111 (40), 14925-14931.

(11) Park, N.-G.; Ryu, K. S.; Park, Y. J.; Kang, M. G.; Kim, D.-K.; Kang, S.-G.; Kim, K. M.; Chang, S.-H., Synthesis and Electrochemical Properties of $\mathrm{V}_{2} \mathrm{O}_{5}$ Intercalated with Binary Polymers. J. Power Sources 2002, 103 (2), 273-279.

(12) Hibino, M.; Ugaji, M.; Kishimoto, A.; Kudo, T., Preparation and Lithium Intercalation of a New Vanadium Oxide with a Two-Dimensional Structure. Solid State Ionics 1995, 79, 239-244.

(13) Galiote, N. A.; Camargo, M. N.; Iost, R. M.; Crespilho, F.; Huguenin, F., Effects of Self-Assembled Materials Prepared from $\mathrm{V}_{2} \mathrm{O}_{5}$ for Lithium Ion Electroinsertion. Langmuir 2011, 27 (19), 12209-12217. 